\title{
Silica exposure, silicosis, and lung cancer: a mortality study of South African gold miners
}

\author{
Eva Hnizdo, G K Sluis-Cremer
}

\begin{abstract}
The effects of exposure to gold mining dust with a high concentration of free silica and tobacco smoking on mortality from lung cancer was assessed in a sample of 2209 white South African gold miners who started mining exposure during 1936-43, and were selected for a study of respiratory disorders in 1968-71 when they were aged 45-54. The mortality follow up was from 1968-71 to 30 December 1986. The relative risk for the effect of dust cumulated to the start of the follow up period was estimated as $1.023(95 \%$ confidence interval (CI) 1.005-1.042) for a unit of 1000 particle-years. The combined effect of dust and tobacco smoking was better fitted by the multiplicative model than the additive model, suggesting that the two exposures act synergistically. No association between lung cancer and silicosis of the parenchyma or pleura was found, but a positive association existed between silicosis of the hilar glands and lung cancer.
\end{abstract}

The issue of carcinogenicity of crystalline silica has been discussed extensively. ${ }^{1-3} \mathrm{~A}$ recent report by the International Agency for Research on Cancer considered that there is sufficient evidence to show that crystalline silica is carcinogenic in experimental animals, but that the evidence for man is limited. ${ }^{3}$

South African gold miners are exposed to several potential risk factors for lung cancer, such as radon daughters, diesel fumes, and respirable dust with a high concentration of free crystalline silica. The concentration of radon daughters is generally considered to be low; the average working level (WL) was estimated as 0.4 , ranging from 0.1 to 3.0 for

Epidemiology Research Unit, Medical Bureau for Occupational Diseases, PO Box 4584, Johannesburg 2000, South Africa

E Hnizdo, G K Sluis-Cremer different mines. ${ }^{4}$ Miners with more than 20 years of gold mining, however, may theoretically accumulate over 100 WLM, a level shown to be associated with an increased risk of lung cancer in a study of underground pyrites miners with a low level of exposure to radon daughters. ${ }^{5}$ About $60-80 \%$ of the mined rock is silica and approximately $30 \%$ of free silica is present in the respirable dust. The concentration of respirable silica considered representative of the mining industry ranges from 0.05 to $0.84 \mathrm{mg} /$ $\mathrm{m}^{3}$ for underground dust ${ }^{6}$; these concentrations have remained more or less unchanged since the 1930s. Tobacco smoking is also highly prevalent among the gold miners; approximately $70 \%$ of the miners were found to be current smokers and $12 \%$ non-smokers in studies done in the 1960 s and 1970 s. $^{78}$

Several studies have reported on the association between mining exposure and lung cancer in white South African gold miners. In a mortality study of a cohort of 3971 white middle aged gold miners, followed up over nine years, 39 deaths due to lung cancer were found, and a standardised mortality ratio (SMR) of $161 \cdot 2\left(95 \%\right.$ CI 114.6-220.3) was reported. ${ }^{9}$ The relative risk (RR) adjusted for smoking, estimated from a nested case-referent study, was 1.77 (95\% CI $0.94 ; 3.31)$ per 10000 particle-years. The results, however, from two case-control studies done on deceased white gold miners showed no association between lung cancer and exposure to gold mining dust, nor any association with radiological silicosis or silicosis identified at necropsy. ${ }^{1026}$

The object of the present paper is to present results from a mortality study of 2209 white South African gold miners who started their mining exposure in 1936-43, and were selected for a study of respiratory disorders during 1968-71, when they were aged 4554. The mortality follow up was over a 17 year period, from 1968-71 to 30 December 1986. In this study, we examined (a) the dose response relation between lung cancer and exposure to silica dust measured in respirable dust particle-years; (b) the combined effect of tobacco smoking and respirable dust particle-years; (c) the association between lung cancer and silicosis identified at necropsy; (d) possible reasons for different results obtained by the case-control studies and follow up studies. 


\section{Materials and methods}

The cohort of 2209 white gold miners represents a sample who were selected in 1968-71, when they were aged $45-54$, for a study of respiratory impairments. ${ }^{8}$ They were subsequently followed up to 30 December 1986. One of the original selection criteria was a minimum of 10 years of underground exposure in gold mines and minimal exposure in other mines. The miners started their exposure between 1936 and 1943 and worked on average 23.5 (SD 4.9) years. ${ }^{8}$

The vital state of the cohort was established from the records of the Provident Fund (a gold miners' pension fund), from the medical files kept at the Medical Bureau for Occupational Diseases (MBOD), and from the Department of Interior. A list of names and dates of birth of all the 2209 miners was sent to the Provident Fund and to the Department of Interior where the miners' vital state was established. The copies of the death registration certificates were obtained from the Department of Interior. The cause of death was established according to the best available evidence by an experienced specialist physician who was not aware of the purpose of the study and who did not consider the exposure to dust or smoking habits when making the diagnosis. Medical files were available on all of the dead miners, and $84.0 \%$ of the deceased miners had had a postmortem examination performed at the National Center for Occupational Health (NCOH) for medicolegal purposes. The ninth revision of the International Classification of Diseases (ICD) code was used.

Of the 2209 miners, 945 (43\%) died during the follow up period. The specialist physician identified 81 deaths from lung cancer (ICD $=162$, ninth revision), according to the best available information from death certificates, medical files, and postmortem reports. These 81 lung cancer deaths were further scrutinised by one of the authors $(S-C)$ and an experienced $\mathrm{NCOH}$ pathologist who had carried out extensive research on lung cancer in gold miners. They rejected four cases because of insufficient evidence that the cancer originated in the lung. Of the 77 accepted cases, 66 were confirmed by a necropsy, five were proven by a biopsy, and six were identified by a death certificate.

The occupational records of the cases of lung cancer were searched to find out if any of the miners had worked as a boilermaker or had had other types of asbestos exposure. Of the 77 miners, one had worked for 1.7 years in a platinum mine; the rest had gold mining exposure only and none had worked as a boilermaker. The occupational exposures recorded in the medical files reliably indicate such exposures.

\section{MINING EXPOSURE}

Occupations in the gold mines were classified on the basis of measured dust counts into 11 groups for which the average respirable dust counts were calculated by Beadle. ${ }^{11}$ For every miner the number of shifts worked in each occupation was weighted by the mean count of respirable dust for that occupational group. The cumulative dust counts and the actual years of exposure were calculated for each decadethat is, the 1940s, 1950s, 1960s, and to the start and to the end of the follow up period in terms of respirable dust particle-years. The exposure before 1940 was added to that for the 1940 s, as it concerned only few miners and small exposures.

\section{SMOKING HABITS}

Full details of smoking habits were obtained during the 1968-71 examination by means of a smoking questionnaire and the reliability of the answers was checked against smoking histories recorded on the medical files kept at MBOD. Tobacco consumption was evaluated in terms of number of cigarettes a day (calculated as an average between the maximum ever smoked and the current consumption), years of smoking (cigarettes or pipe or both), cigarette packyears, and cigarette equivalent pack-years.

\section{LUNG FUNCTION TESTS AND RESPIRATORY SYMPTOMS AND SIGNS}

The information collected during the 1968-71 examination relating to respiration included forced vital capacity (FVC), forced expiratory volume in one second $\left(\mathrm{FEV}_{1}\right)$, forced mid-expiratory flow $\left(\mathrm{FEF}_{25-75 \%}\right)$, assessment of the presence of simple chronic bronchitis by means of a questionnaire, measured sputum volume, and the presence of rhonchi.

\section{METHOD OF ANALYSIS}

Cox's proportional hazards model was applied to select the smoking and gold mining dust exposure variables most strongly related to the presence of lung cancer. ${ }^{12}$ This method of analysis takes into account the individual period of follow up, which is from the start of the follow up to the time when the subject either died or the follow up period ended. The SAS computer program PROC PHGLM ${ }^{13}$ was used. The selection procedure consisted of fitting a set of hierarchical equations to the data. Firstly, the predictive value of each smoking variable was evaluated in a set of models that included age at the start of the follow up. Next, the predictive value of each dust exposure variable was evaluated in a set of models which included age and the best predictor of smoking. The predictive value of each variable was evaluated by means of the log likelihood ratio test $\left(\chi_{\text {LR }}^{2}\right)$.

The combined effect of dust and smoking was assessed by grouping the exposure data and applying the general RR model using the Poisson regression approach. ${ }^{14-17}$ 
The data were cross classified by five age categories $(45-49,50-54,55-59,60-64$, and 65-69), five calendar year at risk categories $(<70,70-74,75$ $79,80-84,>84$ ), four cigarette equivalent packyears categories ( $\leq 10,11-25,26-35, \geq 36$ ), and four categories for particle-years $/ 1000$ cumulated to the start of follow up ( $\leq 15,16-30,31-40,>41)$. The death rates, $h$, within each cell were related to the average dust and smoking level for each cell by means of the function

$$
\mathrm{h}=\mathrm{h}_{0} \cdot \mathrm{R} \text { (dust, smoking; } \beta \text { ), }
$$

where $h_{0}$ denotes the age and year at risk specific disease rate at $R(0)=1$, and $R$ (dust, smoking; $\beta$ ) is the RR function given below by equation (2). Here $\beta$ is the vector of the unknown coefficients. Equation (1) was estimated by the maximum log likelihood function given by Breslow and Day ${ }^{15}$ (page 133).

The general relative risk model proposed by Breslow and Storer ${ }^{18}$ - namely,

$\log (\mathrm{RR})=$

$\left\{\left[1+\beta_{1} \cdot \text { (dust) }+\beta_{2} \cdot \text { (smoking) }\right]^{i}-1\right\} / \lambda, \quad \lambda \neq 0$

$\log (\mathrm{RR})=\log \left\{1+\beta_{1} \cdot\right.$ (dust) $+\beta_{2} \cdot$ (smoking) $\}, \quad \lambda=0$

was applied to determine the shape of the dose response curve,${ }^{19}$ and to calculate the combined effect of dust and smoking. The mixture parameter, $\lambda$, established from the best fitting model, determines whether the combined effect of the two exposures is additive $(\lambda=0)$, multiplicative $(\lambda=1)$, or somewhere in between. For a single exposure model, $\lambda$ determines whether the shape of the dose response curve is linear, exponential, or other form. The goodness of fit of the model was evaluated by the log likelihood ratio statistic $\left(\chi_{\mathrm{LR}}^{2}\right)$. The computer program $\mathrm{GLIM}^{20}$ and the general minimisation program MINUIT $^{21}$ were used to fit the models.

\section{ASSOCIATION BETWEEN LUNG CANCER AND SILICOSIS}

The association between death from lung cancer and the presence of silicosis found at necropsy was examined using the 745 miners who had had a necropsy examination performed by the pathologists at $\mathrm{NCOH}$. The necropsy examinations are for medicolegal purposes, and for every miner silicosis of the parenchyma, pleura, and hilar glands is coded as none, slight, moderate, or marked, according to the findings from a macroscopic examination. The diagnosis is then confirmed by a microscopical examination. The histological examination includes tissue from the upper, middle, and lower zones of both lungs and hilar glands. As the silicotic lesions are unique in appearance the diagnosis is generally considered to be reliable.

The associations between death from lung cancer and the degree of silicosis of the parenchyma, pleura, and hilar glands were examined by crude odds ratios (ORs) and by adjusted ORs estimated from the logistic regression in which the effects of age and dust particle-years were adjusted.

\section{Results}

COMPARISON OF CASES AND THE REST OF COHORT

Table 1 summarises data for the cases and the remainder of the cohort separately. The cases had higher dust particle-year values for all the time intervals examined, but the differences in the actual years of exposure were not as consistent. As expected, smoking for the cases was substantially higher; this was indicated by all the smoking variables examined. The cases had lower lung function measurements $\left(\mathrm{FEV}_{1}, \mathrm{FVC}\right.$, and $\left.\mathrm{FEF}_{25-75 \%}\right)$, and a higher prevalence of respiratory symptoms and signs (simple bronchitis and rhonchi) at the time of the 1969 examination than the rest of the cohort.

\section{SELECTION OF EXPOSURE VARIABLES}

Table 2 shows the sequential results of the hierarchical analyses by the Cox's proportional hazards model applied to the data to select best predictors for smoking and dust. Of the smoking factors examined, cigarette pack-years were most strongly related to death from lung cancer. When the lung cancer cases who had zero value for cigarette pack-years were examined, however, it was observed that some of

Table 1 Comparison of lung cancer cases with rest of cohort

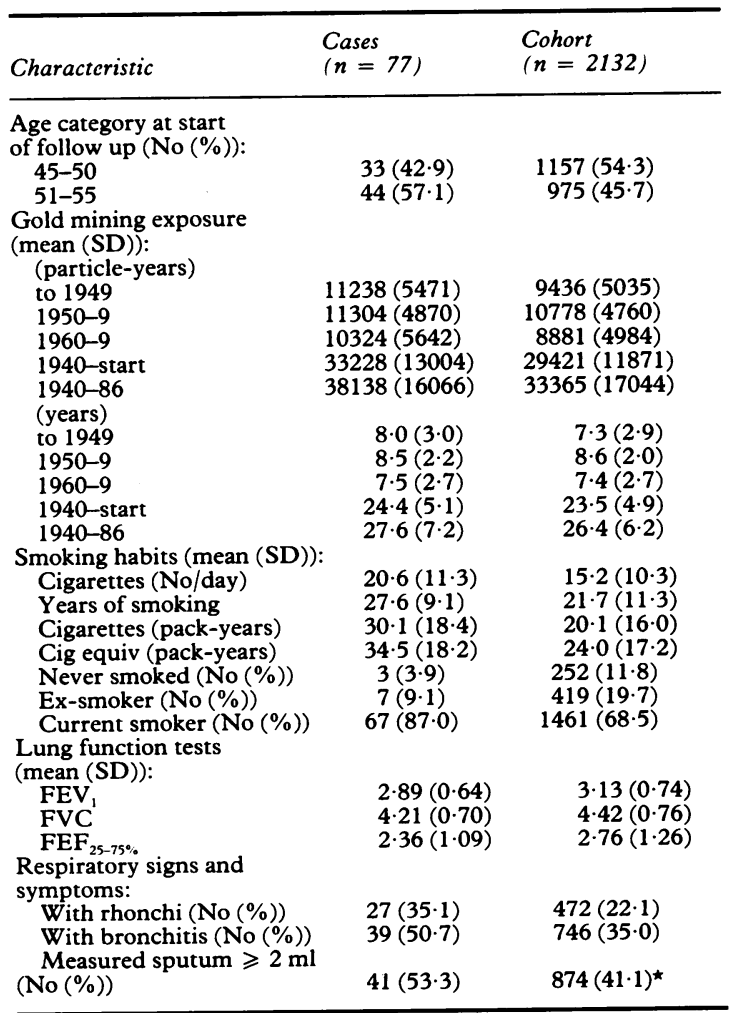

«Three subjects did not have sputum measured. 
Table 2 Results of Cox's proportional hazards model applied to select best predictors of lung cancer

\begin{tabular}{|c|c|c|c|c|c|}
\hline \multirow[b]{2}{*}{ Variable entered into the model } & \multicolumn{3}{|c|}{ Effects included in the model } & \multirow[b]{2}{*}{$-2 \log L$} & \multirow[b]{2}{*}{$\chi^{2}}$, \\
\hline & $\begin{array}{l}\text { Dust } \\
(\beta(S E))\end{array}$ & $\begin{array}{l}\text { Smoking } \\
(\beta(S E))\end{array}$ & $\begin{array}{l}\text { Age } \\
(\beta(S E))\end{array}$ & & \\
\hline $\begin{array}{l}\text { Intercept } \\
\text { Age at start of follow up }\end{array}$ & & & $0.150(0.046)$ & $\begin{array}{l}1142 \cdot 5 \\
1131 \cdot 5\end{array}$ & $11 \cdot 0^{\star \star \star}$ \\
\hline $\begin{array}{l}\text { Smoking variables: } † \\
\text { Cigarettes/day } \\
\text { Years of smoking } \\
\text { Cig equiv pack-years } \\
\text { Cigarette pack-years }\end{array}$ & & $\begin{array}{l}0.046(0.010) \\
0.064(0.015) \\
0.032(0.006) \\
0.033(0.006)\end{array}$ & $\begin{array}{l}0.163(0.046) \\
0.115(0.047) \\
0.125(0.046) \\
0.134(0.046)\end{array}$ & $\begin{array}{l}1111 \cdot 5 \\
1104 \cdot 6 \\
1101 \cdot 9 \\
1101 \cdot 7\end{array}$ & $\begin{array}{l}20 \cdot 0^{\star \star \star} \\
26 \cdot 9^{\star \star \star} \\
29 \cdot 6^{\star \star \star} \\
29 \cdot 8^{\star \star \star}\end{array}$ \\
\hline $\begin{array}{l}\text { Gold mining dust variables: } \ddagger \\
\text { Particle-years to } 1949 / 1000 \\
\text { Particle-years to } 1959 / 1000 \\
\text { Particle-years to start/1000 } \\
\text { Particle-years to } 1986 / 1000 \\
\text { Actual years of mining }\end{array}$ & $\begin{array}{l}0.062(0.023) \\
0.031(0.013) \\
0.023(0.009) \\
0.010(0.003) \\
0.023(0.002)\end{array}$ & $\begin{array}{l}0.033(0.006) \\
0.033(0.006) \\
0.033(0.006) \\
0.033(0.006) \\
0.032(0.006)\end{array}$ & $\begin{array}{l}0.092(0.048) \\
0.103(0.047) \\
0.104(0.046) \\
0.122(0.046) \\
0.115(0.047)\end{array}$ & $\begin{array}{l}1094 \cdot 4 \\
1096 \cdot 4 \\
1095 \cdot 2 \\
1096 \cdot 8 \\
1101 \cdot 0\end{array}$ & $\begin{array}{l}7 \cdot 5^{\star \star} \\
5 \cdot 5^{\star} \\
6 \cdot 7^{\star \star} \\
5 \cdot 1^{\star} \\
0 \cdot 9\end{array}$ \\
\hline
\end{tabular}

${ }^{\star} \mathrm{p}<0.025 ;{ }^{\star \star} \mathrm{p}<0.01 ;{ }^{\star \star \star} \mathrm{p}<0.001$.

†Adjusted for age and fitted independently to the data.

†Adjusted for age and cigarette equivalent pack-years and fitted independently to the data.

them had very high cigarette equivalent pack-years due to pipe smoking, and thus the cigarette equivalent pack-years variable was used in the Poisson regression analysis.

The effect of exposure to gold mining dust, adjusted for age at the start of follow up and cigarette equivalent pack-years, was examined using dust particle-years cumulated to the end of 1949,1959 , to the start of the follow up, and to the end of the follow up, as well as the actual years of exposure. All four particle-year variables were significantly higher for the cases, indicating a higher exposure over the whole period of employment. The regression coefficient for cigarette equivalent pack-years and the contribution in terms of the $\chi^{2}$ value ( $\cong 30$ ) were changed very little by adding the individual dust variables to the model. The dust particle-years cumulated to the start of the follow up were used to evaluate the combined effect. By the start of the follow up, the miners already had on average 24 (SD 5.0) years of underground exposure, and the average exposure after the 1969 examination was only 3.3 (SD 1.8 ) years. The actual duration of the mining exposure was not statistically significant. The correlation coefficient between dust particle-years and cigarette equivalent pack-years estimated on the $\mathbf{2 2 0 9}$ miners was slightly negative $(-0.036)$.

According to the results of the Cox's proportional hazards model the relative risk for lung cancer associated with a unit of 1000 particle-years, cumulated to the start of the follow up period, was $1.023(95 \%$ CI $1.005-1 \cdot 042)$.

\section{COMBINED EFFECT OF DUST AND SMOKING}

Table 3 shows the cohort data cross tabulated by the categories of dust particle-years and cigarette equivalent pack-years. The table shows the number of deaths from lung cancer, person-years, the mean values for dust particle-years cumulated to the start of follow up, cigarette equivalent pack-years, and the observed death rates/1000. This table is summarised over the age and year at risk categories. The mean values for dust and smoking calculated for each cell were used to estimate the dose response trend. In the final analysis there were 272 cells with a non-zero value for person-years.

The marginal adjusted RRs and $95 \%$ CIs indicate an increasing trend for dust and for smoking (table 3 ). The estimates were adjusted for age, year at risk, and the other exposure. The individual dose response curves for dust and smoking were best fitted by the additive model. The differences in the log likelihood, however, for the additive and the multiplicative model were small and statistically insignificant.

The observed death rates per 1000 (h) given in table 4 indicate an increasing trend with smoking, which is consistent for all dust exposure levels. The increasing trend with dust is apparent in the lowest and the highest smoking categories. The steep increase in the highest smoking category suggests that dust and smoking act synergistically.

To assess the combined effect of dust and smoking the Breslow and Storer model, ${ }^{18}$ equation (2), was fitted to the data. The best fit was obtained when $\lambda=$ $0 \cdot 25$, indicating that the combined effect was slightly higher than would be expected from the additivity of the individual effects. The test of $\mathrm{H}_{0}: \lambda=0 \mathrm{v}$ $\mathrm{H}_{\mathrm{a}}: \lambda \neq 1$, 一 that is, the additive $v$ non-additive model, was statistically significant for $\lambda=0.25\left(\chi_{1}^{2}=\right.$ $3.9, \mathrm{p}<0.05)$. Table 4 shows the predicted death rates per 1000 estimated from the models with different values of $\lambda$, and the goodness of fit statistic $\left(\chi_{\mathrm{LR}}^{2}\right)$. The estimated values changed very gradually between $\lambda=1.0$ and $\lambda=0.25$, but for $\lambda=0.0$ (the additive model) the estimated numbers of death for the two highest dust exposure categories were 
Table 3 Number of deaths (d) from lung cancer and person-years of follow up $(P-Y)$ by dust particle-years and cigarette equivalent pack-years

\begin{tabular}{|c|c|c|c|c|c|c|c|}
\hline \multirow{2}{*}{\multicolumn{2}{|c|}{$\begin{array}{l}\text { Dust } \\
\text { (particle-years/1000) }\end{array}$}} & \multicolumn{4}{|c|}{ Cigarette equivalent pack-years } & \multirow{3}{*}{$\begin{array}{r}\text { Total } \\
4 \\
3222\end{array}$} & \multirow{3}{*}{$\begin{array}{l}\begin{array}{l}R R \S \\
(95 \% C I)\end{array} \\
1.00\end{array}$} \\
\hline & & \multirow{2}{*}{$\begin{array}{c}\leq 10 \\
0 \\
838 \\
12.20 \\
1.3 \\
0.0\end{array}$} & \multirow{2}{*}{$\begin{array}{c}11-25 \\
0 \\
1043 \\
11 \cdot 74 \\
18 \cdot 7 \\
0.0\end{array}$} & \multirow{2}{*}{$\begin{array}{c}26-35 \\
2 \\
727 \\
12.99 \\
29 \cdot 6 \\
2.75\end{array}$} & \multirow{2}{*}{$\begin{array}{c}\geq 36 \\
2 \\
614 \\
12 \cdot 11 \\
51 \cdot 4 \\
3 \cdot 26\end{array}$} & & \\
\hline$\leq 15$ & $\begin{array}{l}\text { d } \\
\text { P-Y } \\
\text { dust } \\
\text { cig } \dagger \\
\text { h† }\end{array}$ & & & & & & \\
\hline $16-30$ & $\begin{array}{l}\text { d } \\
\text { P-Y } \\
\text { dust } \\
\text { cig } \\
\text { h }\end{array}$ & $\begin{array}{c}0 \\
3182 \\
22 \cdot 31 \\
2 \cdot 6 \\
0 \cdot 0\end{array}$ & $\begin{array}{c}11 \\
4569 \\
22 \cdot 77 \\
17 \cdot 9 \\
2 \cdot 41\end{array}$ & $\begin{array}{c}9 \\
3133 \\
23 \cdot 54 \\
30 \cdot 3 \\
2 \cdot 87\end{array}$ & $\begin{array}{c}10 \\
3439 \\
21 \cdot 65 \\
47 \cdot 1 \\
2 \cdot 91\end{array}$ & $\begin{array}{r}30 \\
14323 \\
2 \cdot 10\end{array}$ & $\begin{array}{c}1 \cdot 54 \\
(0 \cdot 6-4 \cdot 3)\end{array}$ \\
\hline $31-40$ & $\begin{array}{l}\text { d } \\
\text { P-Y } \\
\text { dust } \\
\text { cig } \\
\text { h }\end{array}$ & $\begin{array}{c}2 \\
2118 \\
35 \cdot 77 \\
2 \cdot 6 \\
0 \cdot 94\end{array}$ & $\begin{array}{c}3 \\
2212 \\
34 \cdot 72 \\
17 \cdot 7 \\
1 \cdot 36\end{array}$ & $\begin{array}{c}3 \\
1482 \\
34 \cdot 74 \\
30 \cdot 2 \\
2 \cdot 02\end{array}$ & $\begin{array}{c}12 \\
1571 \\
34 \cdot 72 \\
47 \cdot 7 \\
7 \cdot 64\end{array}$ & $\begin{array}{l}20 \\
7383 \\
\\
2 \cdot 71\end{array}$ & $\begin{array}{c}2 \cdot 07 \\
(0 \cdot 7-6 \cdot 0)\end{array}$ \\
\hline$\geqslant 41$ & $\begin{array}{l}\mathrm{d} \\
\mathrm{P}-\mathrm{Y} \\
\text { dust } \\
\text { cig } \\
\mathrm{h}\end{array}$ & $\begin{array}{c}3 \\
1708 \\
46 \cdot 57 \\
3 \cdot 2 \\
1 \cdot 76\end{array}$ & $\begin{array}{c}5 \\
1844 \\
47 \cdot 69 \\
17 \cdot 5 \\
2 \cdot 71\end{array}$ & $\begin{array}{c}4 \\
1333 \\
50 \cdot 05 \\
29 \cdot 7 \\
3 \cdot 00\end{array}$ & $\begin{array}{c}11 \\
1179 \\
48 \cdot 68 \\
50 \cdot 0 \\
9 \cdot 33\end{array}$ & $\begin{array}{r}23 \\
6064 \\
\\
3 \cdot 79\end{array}$ & $\begin{array}{c}2.92 \\
(1 \cdot 02-8 \cdot 4)\end{array}$ \\
\hline Total & $\begin{array}{l}\mathrm{d} \\
\mathrm{P}-\mathrm{Y} \\
\mathrm{h} \\
\mathrm{RR} \$ \\
(95 \% \mathrm{CI})\end{array}$ & $\begin{array}{r}5 \\
7846 \\
0 \cdot 64 \\
1 \cdot 00\end{array}$ & $\begin{array}{c}19 \\
9668 \\
1.97 \\
3 \cdot 33 \\
(1 \cdot 3-8 \cdot 9)\end{array}$ & $\begin{array}{c}18 \\
6675 \\
2 \cdot 70 \\
4 \cdot 60 \\
(1 \cdot 7-12 \cdot 4)\end{array}$ & $\begin{array}{c}35 \\
6803 \\
5 \cdot 15 \\
8 \cdot 91 \\
(3 \cdot 5-22 \cdot 7)\end{array}$ & $\begin{array}{r}77 \\
30992\end{array}$ & \\
\hline
\end{tabular}

* Mean value for dust-particle years to start of follow up.

†Mean values for cigarette equivalent pack-years.

$¥$ Mortality per 1000 .

§Adjusted RR estimated from the Poisson multiplicative model.

Table 4 Observed (Obs) and predicted death rates/1000 from models with different values of $\lambda$

\begin{tabular}{|c|c|c|c|c|c|c|c|c|}
\hline \multirow[b]{2}{*}{$C E P Y$} & \multirow[b]{2}{*}{ Dust } & \multirow[b]{2}{*}{$P-Y$} & \multirow{2}{*}{$\begin{array}{l}\text { Obs } \\
\text { death } \\
\text { rates }(h)\end{array}$} & \multicolumn{5}{|c|}{ Estimated death rates $(h)$ for given $\lambda$} \\
\hline & & & & $0 \cdot 0$ & $0 \cdot 25$ & $0 \cdot 50$ & $0 \cdot 75$ & $1 \cdot 0$ \\
\hline$\leq 10$ & $\begin{array}{l}\leq 15 \\
16-30 \\
31-40 \\
\geqslant 41\end{array}$ & $\begin{array}{r}838 \\
3182 \\
2118 \\
1708\end{array}$ & $\begin{array}{l}0 \\
0 \\
0.94 \\
1 \cdot 76\end{array}$ & $\begin{array}{l}0.36 \\
0 \cdot 62 \\
0 \cdot 84 \\
1 \cdot 15\end{array}$ & $\begin{array}{l}0.23 \\
0.48 \\
0.87 \\
1.53\end{array}$ & $\begin{array}{l}0.35 \\
0.58 \\
0.92 \\
1.53\end{array}$ & $\begin{array}{l}0.44 \\
0.66 \\
0.96 \\
1.53\end{array}$ & $\begin{array}{l}0.50 \\
0.70 \\
0.98 \\
1.52\end{array}$ \\
\hline $11-25$ & $\begin{array}{l}\leq 15 \\
16-30 \\
31-40 \\
\geqslant 41\end{array}$ & $\begin{array}{l}1043 \\
4569 \\
2212 \\
1844\end{array}$ & $\begin{array}{l}0 \\
2 \cdot 41 \\
1 \cdot 36 \\
2 \cdot 71\end{array}$ & $\begin{array}{l}1.66 \\
1.90 \\
2 \cdot 12 \\
2.44\end{array}$ & $\begin{array}{l}0.83 \\
1.29 \\
1.90 \\
2.87\end{array}$ & $\begin{array}{l}0.85 \\
1.28 \\
1.84 \\
2.78\end{array}$ & $\begin{array}{l}0.89 \\
1.28 \\
1.80 \\
2.71\end{array}$ & $\begin{array}{l}0.92 \\
1.28 \\
1.77 \\
3.22\end{array}$ \\
\hline $26-35$ & $\begin{array}{l}\leq 15 \\
16-30 \\
31-40 \\
\geqslant 41\end{array}$ & $\begin{array}{r}727 \\
3133 \\
1482 \\
1333\end{array}$ & $\begin{array}{l}2 \cdot 75 \\
2 \cdot 87 \\
2 \cdot 02 \\
3 \cdot 00\end{array}$ & $\begin{array}{l}2 \cdot 66 \\
2 \cdot 92 \\
3 \cdot 19 \\
3 \cdot 46\end{array}$ & $\begin{array}{l}1 \cdot 64 \\
2 \cdot 31 \\
3 \cdot 21 \\
4 \cdot 48\end{array}$ & $\begin{array}{l}1.58 \\
2 \cdot 22 \\
3 \cdot 10 \\
4 \cdot 45\end{array}$ & $\begin{array}{l}1.55 \\
2.15 \\
3.02 \\
4.39\end{array}$ & $\begin{array}{l}1.54 \\
2 \cdot 11 \\
2.97 \\
4.41\end{array}$ \\
\hline$>36$ & $\begin{array}{l}\leq 15 \\
16-30 \\
31-40 \\
\geqslant 41\end{array}$ & $\begin{array}{r}614 \\
3439 \\
1571 \\
1179\end{array}$ & $\begin{array}{l}3.26 \\
2.91 \\
7.64 \\
9 \cdot 33\end{array}$ & $\begin{array}{l}4 \cdot 30 \\
4 \cdot 30 \\
4 \cdot 81 \\
4 \cdot 97\end{array}$ & $\begin{array}{l}3.75 \\
4.33 \\
5.89 \\
7.60\end{array}$ & $\begin{array}{l}3.63 \\
4 \cdot 27 \\
5.97 \\
8.05\end{array}$ & $\begin{array}{l}3.55 \\
4 \cdot 22 \\
6.00 \\
8.37\end{array}$ & $\begin{array}{l}3 \cdot 52 \\
4 \cdot 16 \\
6 \cdot 03 \\
8 \cdot 74\end{array}$ \\
\hline $\begin{array}{l}\text { Total } \\
\chi_{L, R^{\star}}^{2}\end{array}$ & & 30992 & & $141 \cdot 94$ & $138 \cdot 05$ & $138 \cdot 59$ & 138.99 & $139 \cdot 70$ \\
\hline
\end{tabular}

$\star^{\star}$ Degrees of freedom $=267$.

$\mathrm{CEPY}=$ Cigarette equivalent pack-years

underestimated, indicating that the combined effect of dust and smoking is more than additive. As the goodness of fit statistic does not indicate a significant difference between the models with $\lambda=0.25$ and $\lambda=$ 1.0 , we can assume that the combined effect is multiplicative and that the proportionality of hazards applies.
The five cases in the lowest smoking category (table 3) were rechecked for their smoking habits as recorded in the medical files. Three men were found to be lifelong non-smokers and two were moderate pipe smokers. Their actual duration of exposure in the gold mines was high, though, ranging from 24 to 32 years. 
The adjusted $\mathbf{R R}$ for dust estimated by the multiplicative model $(\lambda=1.0)$ was $1.028(95 \%$ CI $1.009-$ 1.048 ) for a unit of 1000 particle-years, which is only slightly higher than the estimate obtained from the Cox's proportional hazards model.

\section{ASSOCIATION BETWEEN LUNG CANCER AND SILICOSIS}

The crude ORs and ORs adjusted for the effect of age at death $\left(\mathrm{OR}_{\mathrm{a}}\right)$, dust particle-years cumulated to the start of the follow up and cigarette equivalent packyears were calculated for the association between lung cancer and silicosis for all the 745 miners who had had a necropsy examination. No association was observed with the presence of silicosis of the lung $\left(\mathrm{OR}_{\mathrm{a}}=0.9,95 \% \mathrm{CI} 0.5-1.6\right)$, or silicosis of the pleura $\left(\mathrm{OR}_{\mathrm{a}}=1 \cdot 2,95 \% \mathrm{CI} 0 \cdot 7-2 \cdot 0\right)$, but there was a positive association with the presence of silicosis of the hilar glands $\left(\mathrm{OR}_{\mathrm{a}}=3.9,95 \% \mathrm{CI} 1 \cdot 2-12 \cdot 7\right)$ (see table 5).

For the 794 miners on which necropsies were carried out the correlation coefficients between cigarette equivalent pack-years and the ordinal categories of silicosis were -0.076 for parenchyma, -0.133 for pleura, and -0.044 for hilar glands. When adjusted for dust and age at death by means of the multivariate linear regression analysis, only the association between silicosis of the pleura and smoking was statistically significant with the regression coefficient $(\beta=-0.006, \mathrm{p}<0.001)$ suggesting a negative association between tobacco smoking and silicosis of the pleura.

\section{Discussion}

The results from this study show a significant dose response relation between death from lung cancer and silica dust particle-years and cigarette equivalent pack-years. The RR for lung cancer associated with the exposure to 1000 particle-years of silica dust standardised for smoking, year of birth, and age, estimated by the proportional hazard model was as $\exp (0.023)=1.023(95 \%$ CI 1.006-1.041). Thus the expected RR for the men in the highest exposure category with an average exposure of about 50000 particle-years, relative to those with less than 15000 but with more than 10 years of gold mining, was $3 \cdot 18$ (95\% CI 1.34-7.45). The range of dust particle-years cumulated to the start of the follow up was 700080000 .

The adjusted $\mathrm{OR}_{\mathrm{a}}$ for lung cancer estimated from the previous mortality study of 3971 miners was 1.77 (95\% CI $0.94-3.31)$ per 10000 particle-years $(\mathrm{p}=0.06)$, and no association between deaths from lung cancer and the duration of underground exposure was observed. ${ }^{9}$ The results obtained from the two follow up studies are in disagreement with the two year of birth matched case-control studies on deceased white South African gold miners, in which no association between lung cancer and dust exposure was found. ${ }^{1026}$ Dust was a significant predictor of mortality from all causes combined. It is possible that by selecting dead controls of the same age at death the two case-control studies were overmatched for dust exposure, and thus did not detect the association, which is not very strong.

The combined effect of dust and smoking appears to be higher than would be expected under the assumption of additivity of the two individual exposures. The power model fitted best at $\lambda=0.25$, and the discrepancies between the expected number of deaths as estimated by the additive model and the observed number of deaths (table 4) indicate some synergism for the highest dust exposure and smoking categories. The goodness of fit statistic indicates that the hypothesis of multiplicativity of the combined effects fits better to the data than additivity. It appears that a synergistic effect between dust and smoking exists for those with more than 35 packyears of smoking and more than 30000 particle-years of dust (table 3). These findings are consistent with the other studies in which the combined effect of exposure to gold mining dust and smoking was evaluated. ${ }^{22}$

No association between silicosis of the parenchyma or pleura and death from lung cancer was seen. The cases with lung cancer had more findings of silicosis in the hilar glands in comparison with those who did not die from lung cancer (table 5). The possibility that this was due to the fact that the cases were

Table 5 Association between death from lung cancer and silicosis of hilar glands

\begin{tabular}{lccccc}
\hline & \multicolumn{2}{l}{ Silicosis of the hilar glands } & & & Total \\
\cline { 2 - 5 } Death from lung cancer & None & Slight & Moderate & Marked & 69 \\
\hline Yes & 3 & 10 & 39 & 17 & 724 \\
No & 109 & 132 & 309 & 174 & $793 \star$ \\
Total & 112 & 142 & 348 & 191 & \\
$\chi^{2}$ for trend $=4 \cdot 5, \mathrm{p}=0.035$ & $1 \cdot 0$ & $2 \cdot 8$ & $4 \cdot 6$ & $3 \cdot 6$ & \\
OR & $1 \cdot 0$ & $2 \cdot 9$ & $4 \cdot 2$ & $3 \cdot 1$ \\
Adjusted OR & & $(0 \cdot 8-10 \cdot 7)$ & $(1 \cdot 3-14 \cdot 0)$ & $(0 \cdot 9-11 \cdot 2)$ & \\
$95 \%$ CI & &
\end{tabular}

^One subject had a missing value for the hilar gland variable. 
heavier smokers and also had heavier exposure to dust, but had no causal association with the development of lung cancer, was also considered. The correlation coefficients for the association of lung cancer with smoking, with dust, and with degree of silicosis of the hilar gland were positive and statistically significant. The correlation between silicosis of hilar glands and smoking was not significant, whereas with dust the correlation was highly significant. The ORs for lung cancer and silicosis of the hilar glands adjusted for dust remained significant, and so did the effect of dust. As exposure to dust and silicosis of the hilar glands are intercorrelated, however, it is difficult to draw a conclusion about their association with lung cancer.

Several possible mechanisms for the effect of silica dust on lung cancer have been suggested. Goldsmith and Guidotti ${ }^{22}$ proposed three interrelated hypotheses to explain the excess of lung cancer in silica exposed workers: (1) silica directly induces lung cancer, (2) silica causes silicosis, which may be an intermediate pathological state leading to lung cancer, and (3) silica combined with polycyclic aromatic hydrocarbons from cigarette smoke impairs lung clearance, thus increasing the effective dose in smokers. Cohen ${ }^{23}$ suggested that cigarette smoke, as well as initiating tumours, may also cause pulmonary insult, which increases the susceptibility to a variety of malignant and non-malignant conditions. Guidotti et al $^{24}$ suggested that lymphatic obstruction by silica-containing macrophages and by silica alone may decrease lymphatic flow, reduce clearance of lymphatic dust, and thus increase residence time of active carcinogens. Archer et $a l,{ }^{25}$ however, argue that silicosis among a group of miners usually reflects the presence of both a siliceous type of ore and poor ventilation; with poor ventilation the miners are also exposed to raised radon daughter concentrations that, they suggest, are responsible for the increased mortality from lung cancer in miners exposed to silica.

This study confirms that an association between lung cancer and exposure to gold mining dust with high concentrations of silica dust is present. The results do not support the hypothesis that silicosis of the parenchyma or pleura is an intermediate pathological state leading to lung cancer. As the intensity of exposure to dust was related to lung cancer, and not the actual duration of the underground exposure, the hypothesis that silica directly induces lung cancer cannot be rejected. There is a possibility, however, that the association between lung cancer and silica dust particle-years in South African gold mines is confounded by the effect of radon daughters, as the increased intensity of dust exposure may be related to increased concentrations of radon daughters. ${ }^{25}$ Further research to consider this issue is required.

The following factors that could have contributed to the presence of positive associations have been examined: asbestos exposure of the cases, positive misclassification of the cases (the cases were rechecked for positive necropsy and biopsy findings by three medical practitioners) and positive misclassification of the dust exposures.

In conclusion, the relative risk of lung cancer associated with 1000 particle-years was estimated as 1.023 (95\% CI 1.005-1.042); the particle-years ranged from 7000 to 80000 for the whole cohort. The combined effect of dust and smoking was adequately fitted by the multiplicative model, indicating the presence of synergism. The OR for the association between lung cancer and silicosis of the hilar gland was $3 \cdot 9(95 \%$ CI $1 \cdot 2-12 \cdot 7)$. No association was found between lung cancer and silicosis of the parenchyma or pleura.

We thank Dr F J Wiles for initiating the collection of the mortality data, Michal Smolka for his help with the data preparation, and the $\mathrm{NCOH}$ pathologists who performed the necropsies.

Requests for reprints to: Mrs Eva Hnizdo.

1 Goldsmith DF, Winn DM, Shy CM, eds. Silica, silicosis, and cancer. Controversy in occupational medicine. Cancer research monographs. Vol 2. New York: Praeger, 1986.

$2 \mathrm{McD}$ (Mnald JC. Silica, silicosis, and lung cancer. $\mathrm{Br} J$ Ind Med 1989;46:289-91.

3 International Agency for Research on Cancer. Monographs on the evaluation of the carcinogenic risk of chemicals to humans. Vol 42. Silica and some silicates. Lyon: IARC, 1987.

4 Wyndham CH, Heyns AJ, Keeley WH, et al. Lung cancer rates among white South African miners. Johannesburg: Chamber of Mines, 1970. (Internal COM research report No 23/70.)

5 Battista G, Belli S, Carboncini F, et al. Mortality among pyrite miners with low-level exposure to radon daughters. Scand $J$ Work Environ Health 1988;14:280-5.

6 Beadle DG, Bradley AA. The composition of airborne dust in South African gold mines. In: Shapiro HA, ed. Pneumoconiosis, proceedings of the international conference, Johannesburg 1969. Cape Town: Oxford University Press, 1970:462-6.

7 Sluis-Cremer GK, Walters LG, Sichel HS. Ventilatory function in relation to mining experience and smoking in a random sample of miners and non-miners. Br J Ind Med 1967;24: 13-25.

8 Wiles FJ, Faure MH. Chronic obstructive lung disease in gold miners. In: Walton WH, ed. Inhaled particles IV, part 2. Oxford: Pergamon Press, 1977:727-35.

9 Wyndham $\mathrm{CH}$, Bezuidenhout BN, Greenacre MJ, SluisCremer GK. Mortality in middle aged South African gold miners. Br J Ind Med 1986;43:677-84.

10 Hessel PA, Sluis-Cremer GK, Hnizdo E. Case-control study of silicosis, silica exposure and lung cancer in white South African gold miners. Am J Ind Med 1986;10:57-62.

11 Beadle DG. The relationship between the amount of dust breathed and the development of radiological signs of silicosis: an epidemiological study of South African gold miners. In: Walton WH, ed. Inhaled Particles III. Oxford: Pergamon Press, 1971:953-64.

12 Cox DR. Regression models and life tables. Journal of the Royal Statistical Society 1972;34:187-220.

13 SAS Institute Inc. SAS/supplemental library user's guide, 5 th ed. Cary, NC: SAS Institute Inc, 1986.

14 Holford TR. The analysis of rates and survivorship using loglinear models. Biometrics 1980;36:229-306.

15 Breslow NE, Day NE. Statistical methods in cancer research. Vol 2. The design and analysis of cohort studies. Lyon: International Agency for Research on Cancer, 1987. 
16 Lubin JH, Gaffey W. Relative risk models for assessing the joint effects of multiple factors. Am J Ind Med 1988;13:149-67.

17 Frome EL, Checkoway $H$. Use of poisson regression models in estimating incidence rates and ratios. $\mathrm{Am} J$ Epidemio 1985;121:309-23.

18 Breslow NE, Storer BE. General relative risk functions for casecontrol studies. Am J Epidemiol 1985;122:149-62.

19 Moolgavkar SH, Venzon DJ. General relative risk regression models for epidemiological studies. $A m$ J Epidemiol 1987;126:949-61.

20 Baker RJ, Nelder JA. The GLIM system: Release 3. Oxford: Numerical Algorithms Group, 1978.

21 James F, Roos M. "MINUIT"-A system for function minimization and analysis of the parameter errors and correlations. Computer Physics Communications 1975;10:343-67.

22 Goldsmith DF, Guidotti TL. Combined silica exposure and cigarette smoking: a likely synergistic effect. In: Goldsmith DF, Winn DM, Shy CM, eds. Silica, silicosis, and cancer. Controversy in occupational medicine. Cancer Research Monographs, Vol 2. New York: Praeger, 1986:451-9.
23 Cohen $\mathrm{BH}$. Is pulmonary dysfunction the common denominator for the multiple effects of cigarette smoking? Lancet 1978;ii:1024-7.

24 Guidotti TL, Coley BD, Goldsmith DF. Silica exposure and intrathoracic lymphatic changes. In: Goldsmith DF, Winn DM, Shy CM, eds. Silica, silicosis, and cancer. Controversy in occupational medicine. Cancer Research Monographs. Vol 2. New York: Praeger, 1986:147-55.

25 Archer VE, Roscoe JR, Brown D. Is silica or radon daughters the important factor in the excess lung cancer among underground miners? In: Goldsmith DF, Winn DM, Shy CM, eds. Silica, silicosis, and cancer. Controversy in occupational medicine. Cancer Research Monographs. Vol 2. New York: Praeger, 1986:375-384.

26 Hessel PA, Sluis-Cremer GK, Hnizdo E. Silica exposure, silicosis, and lung cancer: an autopsy study. $\mathrm{Br} J$ Ind Med 1990;47:4-9.

Accepted 23 July 1990

\section{Destruction of manuscripts}

From 1 July 1985 articles submitted for publication will not be returned. Authors whose papers are rejected will be advised of the decision and the manuscripts will be kept under security for three months to deal with any inquiries and then destroyed. 